\title{
Analysis of Allopurinol, Cucurbitacin B, Morindine, and Piperine as Xanthine Oxidase Inhibitor by Molecular Docking
}

\author{
Lailatul Fitria ${ }^{1}$, Muhammad Hermawan Widyananda ${ }^{1}$, Sefihara Paramitha Sakti ${ }^{{ }^{*}}$ \\ ${ }^{1}$ Department of Biology, Faculty of Mathematics and Natural Sciences, Brawijaya University \\ Jalan Veteran Malang East Java Indonesia 65145
}

Submission: August 2019; Revised: September 2019: Accepted: October 2019

*Corresponding author: Sefihara Paramitha Sakti; e-mail: sefiharaa@gmail.com

\begin{abstract}
Xanthine oxidase (XO) was known to be involved in the mechanism of ROS and uric acid production. XO inhibitor plays role in preventing changes in purines to uric acid so uric acid levels in serum and urine can be reduced. There were potential compounds acted as good XO inhibitors, namely cucurbitacin B, morindin, and piperine. The aim of this study was to analyze the interactions between XO and allopurinol, cucurbitacin B, morindin, or piperine by molecular docking to predict the XO inhibitor potent of those compound. We obtained XO (1FIQ) from RCSB database, allopurinol (CID135401907), cucurbitacin B (CID5281316), morindin (CID151621), and piperine (CID638024) from PubChem database. Molecular docking was done using Hex 8.0. The docking results were visualized with Discovery Studio 3.5. The interaction of cucurbitacin B with XO and morindin with XO resulted in low docking energy, -375.08 $\mathrm{kcal} / \mathrm{mol}$ and $-377.4 \mathrm{kcal} / \mathrm{mol}$. The docking energy of piperine with XO and allopurinol with XO was $-163.32 \mathrm{kcal} / \mathrm{mol}$ and $-281.4 \mathrm{kcal} / \mathrm{mol}$. Cucurbitacin B and morindin bound to the active site of XO precisely on the FAD domain involving ARG426, ALA338, and ASP360. Both of the compounds established more than 10 bonds of van der Waals when interacted with XO. Piperine and allopurinol bound to $\mathrm{XO}$ near the $\mathrm{Fe}_{2} \mathrm{~S}$ cofactor. This study has shown that cucurbitacin B and morindin had high potential as XO inhibitors because they bind to XO on the FAD side such as benzimidazole.
\end{abstract}

Keywords: allopurinol; cucurbitacine B; morindin; piperin; xanthine oxidase

\section{INTRODUCTION}

Xanthine oxidase is the part of the flavin hydroxylase molybdenum iron-sulfur enzyme. Xanthine oxidase is a homodimer protein that has a molecular weight of $290 \mathrm{kDa}$. Xanthine oxidase has 2 flavin compounds (FAD), 2 molybdenum atoms, and $\mathrm{Fe}$ atoms [1]. Xanthine oxidase consists of 3 domain, namely molybdenum center, flavin adenine nucleotide (FAD) cofactor, and two iron sulphur centers $[2 \mathrm{Fe}-2 \mathrm{~S}]$. Xanthine oxidase is known to be involved in the reactive oxygen species (ROS) production mechanism. ROS are related to physiopathology in humans. Oxidative stress caused by an imbalance between antioxidants and the production of oxidants, including ROS, is known to contribute to the degenerative process. Xanthine oxidase enzyme is one of the ROS sources. The xanthine oxidase enzyme catalyses the reaction of hypoxanthine to xanthine and xanthine to uric acid [2].

High urid concentrations play a role in complications of several diseases such as gout, kidney disease, and acute arthritis. Production of uric acid can be reduced by the presence of xanthine oxidase inhibitor. The xanthine oxidase inhibitor that has been widely used for treatment is allopurinol. Allopurinol and oxypurinol are known to be able to inhibit changes in purines to uric acid so that uric acid levels in serum and urine can be reduced [3-5]. Oxidative stress can be prevented by plants. Plants have high antioxidant compounds that have been known to have free radical scavenging activity. The antioxidant compounds are able to reduce ROS by scavenging free radicals, damaging chain reactions, and attaching to metal ions [6]. Natural bioactive or secondary metabolites such as alkaloids, phenolics, tannins, flavonoids, and coumarins are known to have the activities of xanthine oxidase inhibition [7].

Secondary metabolites that can be found in vegetable, fruit, plants, and other have a role as an anti-cancer, anti-allergic, antioxidant, antiinflammatory, and inhibitor of certain enzymes [8]. Cucurbitacin B, morindin, and piperin have the ability as antioxidant. Cucurbitacin B is one type of Cucurbitacin that isolated from Cucurbitaceae. Cucurbitacin B is known to have anti-inflammatory and is widely used as traditional medicines [9]. This compound have chemopreventive and anticarcinogenic activity [10]. Piperine is known to have anti-diabetic, anti-bacteria, anti-depressant, antioxidant, anti-inflammatory, and anti-tumor. Piperine is also known to have the ability to inhibit xanthine oxidase up to $70.9 \%$ [11]. This study aimed to analyze the interactions between $\mathrm{XO}$ and 
allopurinol, cucurbitacin B, morindin, or piperine by molecular docking to predict the XO inhibitor potent of those compound.

\section{METHODS}

\section{Protein and Ligand Preparation}

Structure of Xanthine Oxidase was obtained from the PDB (https://www.rcsb.org/) database with the ID: 1FIQ. Ligands were downloaded through the PubChem (https://pubchem.ncbi.nlm.nih.gov/) database as 3D SD-format. The compounds used were allopurinol (ID: 135401907), cucurbitacin B (ID: 5281316), morindin (ID: 151621), and piperine (ID: 638024). Protein was prepared by Discovery Studio 2016 Client software to remove the water molecules and ligands. Ligands were prepared to minimize energy using Open Babel in PyRx 0.8 software. Files were converted to PDB format.

\section{Docking of Protein-Ligand and Visualization}

Docking was done by HEX 8.0.0 to predict the possible interaction and energy binding of $\mathrm{XO}$ allopurinol, XO-cucurbitacin $\mathrm{B}, \mathrm{XO}$-morindin, and XO-piperine. HEX 8.0.0 was used because it could determine the bonding side and the active side of receptor or ligand. The type of correlation used was Shape + Electro + DARS, but other types of correlations that could be used was Shape only, Shape + Electro, and Shape + DARS. The output of the docking was visualized using Discovery Studio 2016 Client to analyze the interaction.

\section{RESULTS AND DISCUSSIONS}

The inhibition characteristic of a compound against $\mathrm{XO}$ enzyme is determined by the position of that interaction. The Xanthine oxidase enzyme is in the form of a homodimer which each sub-unit had an active site. Each unit consists of 3 domains, namely the molybdopterin domain (largest), FAD binding domain (intermediate), and $\mathrm{N}$-terminal domain (smallest). The cofactors of molybdopterin, [2Fe-2S], and FAD are responsible for redox reactions with substrates. The domain of molybdopterin functioned as a substrate binding site where the oxidation reaction occurred. While in the $\mathrm{N}$-terminal domain there are $\mathrm{Fe}$ / S I and Fe / S II cofactors which function as electron transfer bridges from Molybdopterin to FAD [12]. The docking results between allopurinol and $\mathrm{XO}$ produced six bonds outside the active side of the enzyme. This interaction occurred among molybdopterin, $\mathrm{N}$-terminal, and FAD binding domain (Figure 1). The hydrogen bonds formed included the ARG1222, SER1225, and GLU45 amino acid residues. Hydrophobic bonds occurred between allopurinol and ARG122. Two electrostatic bonds occurred between allopurinol and ASP429 (Table 1). In addition, there were five Van der Waals bonds in this interaction. The docking energy was -163.32 $\mathrm{kcal} / \mathrm{mol}$. Allopurinol is the most commonly used XO inhibitor in the medical world. The structure of allopurinol is almost similar to that of hypoxanthine and xanthine as XO substrate so that it is easy to bind to XO. In this study, allopurinol did not bind to the active side of XO. Although allopurinol did not bind to the active side of $\mathrm{XO}$, allopurinol had the effect of inhibiting XO activity because it could act as a noncompetitive inhibitor [13]. Based on previous research, allopurinol at low concentrations acted as a competitive inhibitor of XO enzymes and at higher concentrations became a non-competitive inhibitor [14].

In previous studies, cucurbitacin B had been shown to have high antioxidant and the ability as inhibitors of several enzymes [15]. The character of cucurbitacin B was in accordance with the results of this study. The cucurbitacin B acted as an XO inhibitor so that superoxide anion free radicals were not formed. The docking results showed an interaction between cucurbitacin B and XO occurred in the active site, precisely in FAD site (Figure 1). In total, there were more than ten bonds in this interaction. Hydrogen bonds occurred between cucurbitacin B with LYS422, LYS1228, ASP360, and PHE337. Hydrophobic bonds were established between cucurbitacin B with ALA338, ILE358, LYS433, ARG426, and PHE337 (Table 1). Its docking energy was $-375.08 \mathrm{kcal} / \mathrm{mol}$. This interaction contained 15 Van der Waals bonds. In addition, there were also an unfavorable bump and an unfavorable acceptor-acceptor. It indicated that cucurbitacin B had potential as a competitive inhibitor of the XO enzyme. The docking energy of cucurbitacin $\mathrm{B}$ was also smaller than allopurinol so that it was easier to bond with XO [16]. XO has two types of inhibitors, namely inhibitors that bind to the purin binding site and inhibitors that bind to the FAD site such as benzimidazole. Benzimidazole is a heterocyclic aromatic organic compound composed of fused aromatic and imidazole rings. The reaction sequence was the oxidative hydroxylation reaction occurred in the molybdenum center which reduced Mo VI to Mo IV. In the first half reaction of catalysis, two electrons were transferred from the substrate to the Molybdenum center and then transferred to FAD via $\mathrm{Fe} / \mathrm{S}$. In this FAD site, there is a reduction in $\mathrm{O}_{2}$ molecules to $\mathrm{O}_{2-}$. Half of the oxidation reaction in molybdopterin occurs together with the reduction reaction on the FAD site [17]. Thus, in the FAD Domain occurred reduction of Oxygen molecular. The $\mathrm{O}_{2}$ is reduced to $\mathrm{O}_{2}$ - which is a reactive free radical. Therefore, the FAD domain is the domain that is responsible for producing free radicals [18]. 

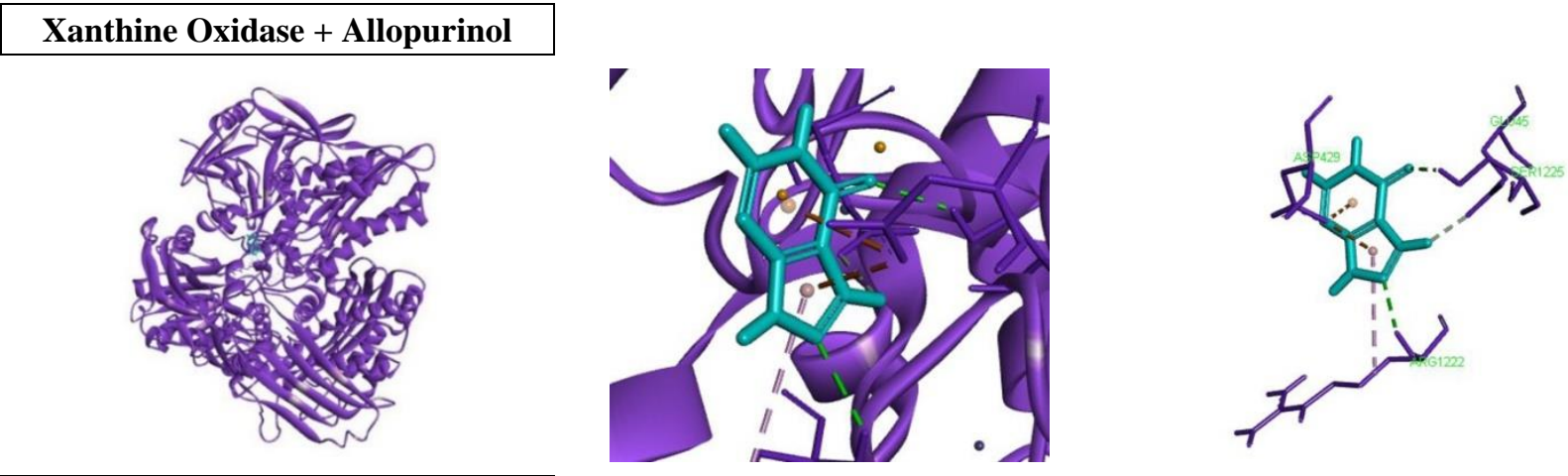

Xanthine Oxidase + Cucurbitacin
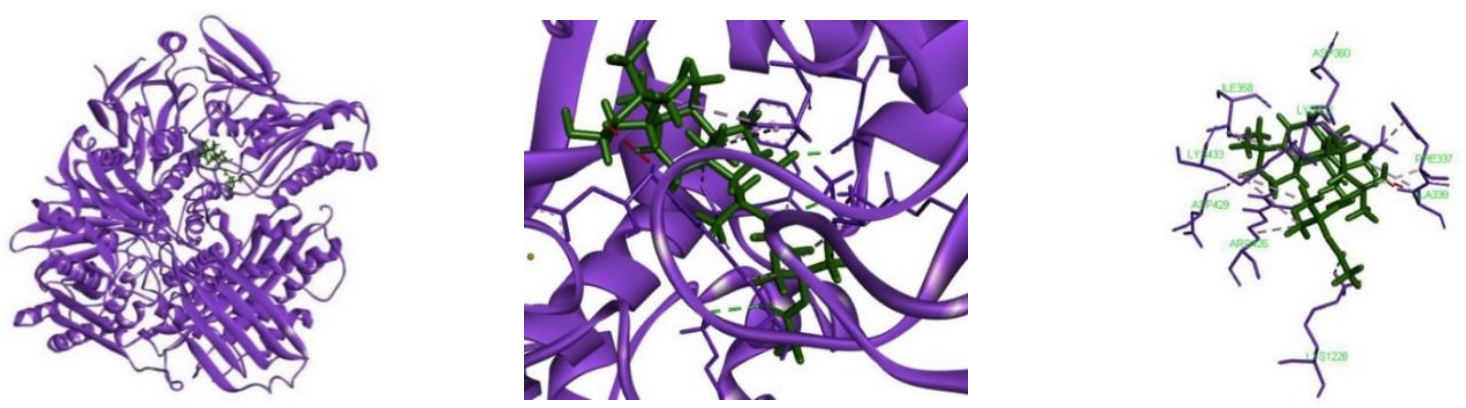

Xanthine Oxidase + Morindin
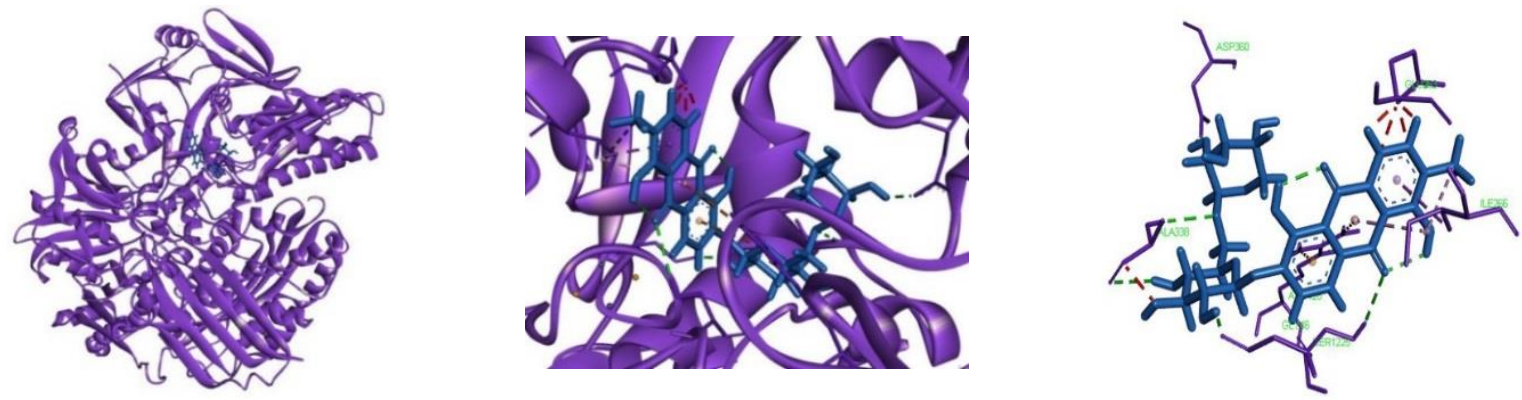

\section{Xanthine Oxidase + Piperine}
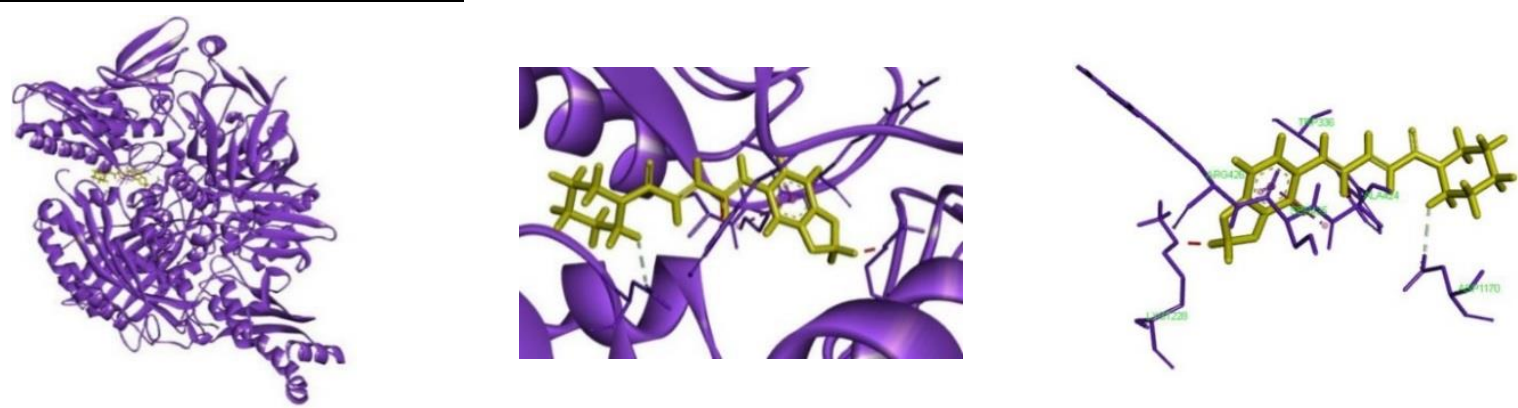

Figure 1. Visualization of Xanthine Oxidase Enzyme and Allopurinol, Cucurbitacin B, Morindin or Piperine Interaction

Morindin is a phenol compound in the anthraquinone group found in noni fruit (Morinda citrifolia). The previous study stated noni fruit extract has good antioxidant potential [19]. Another study also reported that Noni fruit extract had a high Xanthine Oxidase inhibitor effect [20]. The docking energy generated from the interaction between morindin and XO was $-377.4 \mathrm{kcal} / \mathrm{mol}$. This interaction occurred in the active site precisely in FAD site (Figure 1). The bonds formed in this interaction were also more than 10 bonds. Hydrogen bonds occurred at ALA338, SER1225, ALA338,
GLY46, ASP360, on the $\mathrm{H}$ atoms with $\mathrm{O}$ on ligands molecule. There were also electrostatic bonds and hydrophobic bonds involving the ARG426 and ILE266, respectively (Table 1). In addition, this interaction involved 18 van der Waals bonds and two unfavourable bumbs. Morindin bound to the active side of XO with lower energy and had more Van der Waals bonds than allopurinol. Based on the docking results, it can be concluded that morindin was more effective as XO inhibitor than allopurinol. The character of morindine inhibition is similar to benzimidazole which bind to the FAD site of XO. 
Fitria, L., Widyananda, M.H., Sakti, P.S. - Analysis of Allopurinol, Cucurbitacin B, Morindine, and Piperine as Xanthine Oxidase

Table 1. Types of interaction between xanthine oxidase enzyme with allopurinol, cucurbitacin B, morindin, or piperine

\begin{tabular}{|c|c|c|c|c|c|c|}
\hline Interactions & Name & $\begin{array}{c}\text { Distance } \\
\text { (§) }\end{array}$ & Category & Type & $\begin{array}{c}\text { From } \\
\text { Chemistry }\end{array}$ & $\begin{array}{c}\text { To } \\
\text { Chemistry }\end{array}$ \\
\hline \multirow{6}{*}{$\begin{array}{l}\text { Xanthine } \\
\text { Oxidase - } \\
\text { Allopurinol }\end{array}$} & $\begin{array}{l}\text { C:ARG1222:HN } \\
- \text { :LIG1:N }\end{array}$ & 2.6019 & Hydrogen Bond & $\begin{array}{c}\text { Conventional } \\
\text { Hydrogen Bond }\end{array}$ & H-Donor & H-Acceptor \\
\hline & $\begin{array}{l}\text { C:SER1225:HG } \\
- \text { :LIG1:O }\end{array}$ & 2.21868 & Hydrogen Bond & $\begin{array}{c}\text { Conventional } \\
\text { Hydrogen Bond }\end{array}$ & H-Donor & H-Acceptor \\
\hline & $\begin{array}{l}\text { :LIG1:H - } \\
\text { A:GLU45:OE2 }\end{array}$ & 2.93898 & Hydrogen Bond & $\begin{array}{c}\text { Carbon } \\
\text { Hydrogen Bond }\end{array}$ & H-Donor & H-Acceptor \\
\hline & $\begin{array}{l}\text { B:ASP429:OD2 } \\
- \text { :LIG1 }\end{array}$ & 3.67409 & Electrostatic & Pi-Anion & Negative & Pi-Orbitals \\
\hline & $\begin{array}{l}\text { B:ASP429:OD2 } \\
- \text { :LIG1 }\end{array}$ & 3.95062 & Electrostatic & Pi-Anion & Negative & Pi-Orbitals \\
\hline & $\begin{array}{l}\text { :LIG1 - } \\
\text { C:ARG1222 }\end{array}$ & 4.57635 & Hydrophobic & Pi-Alkyl & Pi-Orbitals & Alkyl \\
\hline \multirow{5}{*}{$\begin{array}{l}\text { Xanthine } \\
\text { Oxidase - } \\
\text { Cucurbitacin } \\
\text { B }\end{array}$} & $\begin{array}{l}\text { :LIG1:H - } \\
\text { B:ASP360:OD2 }\end{array}$ & 1.75584 & Hydrogen Bond & $\begin{array}{c}\text { Conventional } \\
\text { Hydrogen Bond }\end{array}$ & H-Donor & H-Acceptor \\
\hline & $\begin{array}{l}\text { B:PHE337:CA - } \\
: L I G 1: O\end{array}$ & 2.87219 & Hydrogen Bond & $\begin{array}{c}\text { Carbon } \\
\text { Hydrogen Bond }\end{array}$ & H-Donor & H-Acceptor \\
\hline & $\begin{array}{l}\text { B:ALA338 - } \\
: L I G 1: C\end{array}$ & 3.90036 & Hydrophobic & Alkyl & Alkyl & Alkyl \\
\hline & $\begin{array}{l}\text { :LIG1:C - } \\
\text { B:ARG426 }\end{array}$ & 3.12174 & Hydrophobic & Alkyl & Alkyl & Alkyl \\
\hline & $\begin{array}{l}\text { B:PHE337 - } \\
\text { :LIG1:C }\end{array}$ & 4.26355 & Hydrophobic & Pi-Alkyl & Pi-Orbitals & Alkyl \\
\hline \multirow{6}{*}{$\begin{array}{l}\text { Xanthine } \\
\text { Oxidase - } \\
\text { Morindin }\end{array}$} & $\begin{array}{l}\text { B:ALA338:HN - } \\
\text { :LIG1:O }\end{array}$ & 2.60481 & Hydrogen Bond & $\begin{array}{c}\text { Conventional } \\
\text { Hydrogen Bond }\end{array}$ & H-Donor & H-Acceptor \\
\hline & $\begin{array}{l}\text { :LIG1:H - } \\
\text { B:ALA338:O }\end{array}$ & 2.92157 & Hydrogen Bond & $\begin{array}{c}\text { Conventional } \\
\text { Hydrogen Bond }\end{array}$ & H-Donor & H-Acceptor \\
\hline & $\begin{array}{l}\text { :LIG1:H - } \\
\text { A:GLY46:O }\end{array}$ & 1.91068 & Hydrogen Bond & $\begin{array}{c}\text { Conventional } \\
\text { Hydrogen Bond }\end{array}$ & H-Donor & H-Acceptor \\
\hline & $\begin{array}{l}\text { :LIG1:H - } \\
\text { B:ASP360:OD2 }\end{array}$ & 2.07689 & Hydrogen Bond & $\begin{array}{l}\text { Conventional } \\
\text { Hydrogen Bond }\end{array}$ & H-Donor & H-Acceptor \\
\hline & $\begin{array}{l}\text { B:ARG426:NH1 } \\
- \text { :LIG1 }\end{array}$ & 4.67203 & Electrostatic & Pi-Cation & Positive & Pi-Orbitals \\
\hline & $\begin{array}{l}\text { B:ARG426:NH2 } \\
- \text { :LIG1 }\end{array}$ & 4.63592 & Electrostatic & Pi-Cation & Positive & Pi-Orbitals \\
\hline \multirow{3}{*}{$\begin{array}{l}\text { Xanthine } \\
\text { Oxidase - } \\
\text { Piperine }\end{array}$} & $\begin{array}{l}\text { :LIG1:H - } \\
\text { C:ASP1170:OD2 }\end{array}$ & 2.50865 & Hydrogen Bond & $\begin{array}{c}\text { Carbon } \\
\text { Hydrogen Bond }\end{array}$ & H-Donor & H-Acceptor \\
\hline & $\begin{array}{l}\text { B:ALA424:C,O; } \\
\text { SER425:N - :LIG1 }\end{array}$ & 4.02256 & Hydrophobic & $\begin{array}{c}\text { Amide-Pi } \\
\text { Stacked }\end{array}$ & Amide & Pi-Orbitals \\
\hline & $\begin{array}{l}\text { B:SER425:C,O; } \\
\text { ARG426:N - :LIG1 }\end{array}$ & 4.74918 & Hydrophobic & $\begin{array}{l}\text { Amide-Pi } \\
\text { Stacked }\end{array}$ & Amide & Pi-Orbitals \\
\hline
\end{tabular}

Piperin is one of the alkaloid compounds contained in the Piperaceae family. Piper plant has anthelmintic, anti-asthmatic, painkiller, relief insomnia, and epilepsy [21]. Based on the previous research, Piper betle and Piper niruri extract containing alkaloid compounds have high xanthine oxidase inhibitor activity [22]. The interaction between piperine and $\mathrm{XO}$ in this study showed the docking energy produced was $-281.4 \mathrm{kcal} / \mathrm{mol}$. This interaction took place out of the active site, precisely between FAD binding domain and molybdopterin domain. The amino acid residues involved in the interaction were ASP11, ALA424, SER425, and ARG426. The hydrogen bond occurred with ASP1170. The hydrophobic bonds involved ALA424 and SER425. There were also two unfavourable bumps and one van der Waals bond.

In our study, morindin and cucurbitacin had the best potential as XO inhibitor. Morindin and cucurbitacin bound to the active site located in FAD domain of Xanthine oxidase. It indicated that they were non-competitive inhibitors. Both of these molecules had more hydrogen bonds and Van der Waals force bonds compared to allopurinol which in 
previous studies proved to be XO inhibitor. Even the two compounds had the energy docking much lower than allopurinol so that they were easier to bind to XO. Piperine also had lower docking energy than allopurinol. The low energy docking can be influenced by the Van der Waals interaction on an enzyme-ligand bond. The presence of Van der Waals in an interaction changed the conformation of alanine polypeptide which results in increased thermal stability of an interaction [23]. The strength of the interaction between the protein and the ligand was also determined by the distance between the bound atoms which in the Table 1 above is represented in Distance. Distance in the docking data represented the distance between the donor and the acceptor. The closer distance between two atoms means more energy needed to separate them and vice versa [25]. The inhibition mechanism of a compound against enzymes can be divided into two namely competitive inhibition and non-competitive inhibition. Competitive inhibition occurs when inhibitors have structures that are very similar to the substrate, resulting in competition between both to bind to the active site of the enzyme. In this inhibition type, Only one of the inhibitor or substrate can bind to the enzyme, If the inhibitor bound to the enzyme, the substrate could not bind to the enzyme and vice versa. Contrast to non-competitive inhibition, noncompetitive inhibitions occurred when the inhibitor bound not to the active site of the enzyme. The substrate can still bind to the enzyme even though the enzyme had bound to the inhibitor. However, the enzyme was inactive [24].

\section{CONCLUSION}

Cucurbitacin B and morindin bound to the active site of XO with higher affinity than allopurinol. Piperine bound to XO, not in the active site but had a slightly higher affinity than allopurinol. Based on the effectiveness of the energy docking from interaction $\mathrm{XO}$ toward curcubitacin $\mathrm{B}$ or $\mathrm{XO}$ toward morindin, cucurbitacin $\mathrm{B}$ and morindin could be potential inhibitors of $\mathrm{XO}$ and led to the growing interest in the investigation of herbal medicine.

\section{ACKNOWLEDGEMENTS}

The authors are sending our thanks to our research group for helping authors to finish this research.

\section{REFERENCES}

1. Muthuswamy U, Preetha RP, Kuppusamy A, Thirumalaisamy S, Varadharajan S, Puliyath J, Arumugam M, Int J Pyhto, 2012, 2(5), 135-142.
2. Danijela AK, Danica SD, Gordana SS, Ivan RP, Aleksandra SD, Jovana DI, Journal of Chemistry, 2015, 1-8.

3. Ken O, Teruo K, Takeshi N, Current Pharmaceutical Design, 2013, 19, 2606-2614.

4. Nadiezhda CM, Eric EK, Redox biology, 2013, 1, 353-358.

5. Shalini KM, Naira N, RRJMHS, 2014, 3(3), 413.

6. Manzoor AS, Sowriappan JDB, Shabir AM, Meat Sciences, 2014, 98, 21-33.

7. Ling X, Bochu W, Pharmazie, 2014, 69, 243 256.

8. Lin S, Zhang G, Liao Y, Pan J, and Gong D, Journal of Agricultural and Food Chemistry, 2015, 63 (35), 7784-7794.

9. Qian Z, Yunyi L, Weiwei L, fengyun M, Yi Z, Mingjie C, Junli C, Yuesheng W, Guangxiao Y, Guangyuan H, Molecular Medicine Reports, 2014, 10(1), 89-94.

10. Mohar V R, Dos A, and Tresina P S, Ethnomedicinal Plants with Therapeutic Properties, 2019, Apple Academic Press, Canada.

11. Luxita S, Zarrin A, International Journal of Research in Social Sciences, 2018, 253-267.

12. Okamoto K, Kusano T, and Nishino T, Current Pharmaceutical Design, 2013, 19, 2606-2614.

13. Peglow S, Alexander H, Toledo, Roberto A, Fernando L, Luis $\mathrm{H}$, and Toledo $\mathrm{P}, J$ Hepatobiliary Pancreat Sci, 2013, 18, 137-146.

14. Alirezaei A, Argani H, Asgharpour M, Bahadorimonfared A, and Bakhtiar M, J Renal Inj Prev 2017, 6(4), 297-302.

15. Jayaprakasam B, Seeram NP, dan Nair MG. Anticancer and antiinflammatory activities of cucurbitacins from Cucurbita andreana. Cancer Letter; 189:11-16.

16. He W, Su G, Sun-Waterhouse D, Waterhouse GIN, Zhao $\mathrm{M}$, and Liu Y. In vivo antihyperuricemic and xanthine oxidase inhibitory properties of tuna protein hydrolysates and its isolated fractions. Food Chemistry 2019; 272:453-461.

17. Borges, F., E. Fernandes, and F. Roleira, Current Medicinal Chemistry, 2003, 9, 195-217.

18. Cantu-Medellin N and Kelley E E 2013 Redox Biology 1: 353-358.

19. Kurniawan D, Jurnal Ilmu-Ilmu Peternakan, 28(2), 105-111.

20. Palu A, Deng S, West B, and Jensen J, Phytotherapy research, 2009, 23, 17901791.

21. Gutierrez RMP, Gonzales AMN, dan HoyoVadillo C. Mini Rev Med Chem, 2013, 13(1), 130.

22. Vikrama CP, Murugesan S, Arivuchelvan A, Sukumar K, Arulmozhi, and Jagadeeswaran A, 
Fitria, L., Widyananda, M.H., Sakti, P.S. - Analysis of Allopurinol, Cucurbitacin B, Morindine, and Piperine as Xanthine Oxidase

Journal of Pharmacognosy and Phytochemistry, 2018, 7(5), 959-961.

23. Tkatchenko A, Rossi M, Blum V, Ireta J, and Scheffler M, 2011, 106, 1-4.

24. Aldred, E. M., C. Buck, and K. Vall., Pharmacology:
A handbook for Complementary Healthcare Professionals. 2009. Churchill Livingstove. Ediburg. 25. Berg J M, Tymoczko J L, Stryer L, Biochemistry, Fifth Edition, 2002, W. H. Freeman and Company, San Francisco. 